\title{
little-known facts about silicate bricks and fires
}

\author{
Alexandr Ibragimov* \\ Moscow State University of Civil Engineering, 26, Yaroslavskoe Shosse, Moscow, Russia
}

\begin{abstract}
The article presents a brief historical background about the epistemology of silicate brick. Well-known facts about silicate brick are given: the technological scheme of manufacture, modern grades for strength and frost resistance, information about thermal conductivity, classification by species, size and purpose. Advantages are considered, among which are noted: relatively low cost, environmental friendliness, compatibility with masonry mortars, aesthetics, wide color gamut, good geometric parameters, high strength characteristics, good soundproof ability, relatively high frost resistance, ease of processing. Disadvantages are given, among which are noted: high thermal conductivity, high water absorption, brittleness, and instability to acidic and alkaline aggressive environments. Particular attention is given to the consideration of the behavior of silicate brick and masonry from it in a fire. References to works devoted to this problem are given. The research of high temperature effects on the brickwork of the silicate bricks in the fire was held. A model for the possible collapse of brickwork as a re-sult of reducing its bearing ability due to fire was designed. The conclusion is drawn about the need for technical diagnostics of the structures of buildings made of silicate brick exposed to fire, as well as the special tactics of extinguishing fires in such buildings.
\end{abstract}

\section{Introduction}

"Experiments with a long-known mixture of lime and sand began almost simultaneously by the Russian civil engineer Prokhov and Swede Ridin, they tried to make walls and even whole houses industrially from it, as it was understandably impossible to achieve high quality (the more so, concrete based on Portland cement was already widely used ) A bit further German physician (not a builder !!!) Bernardi moved on, he made pressed bricks, which then hardened in the air. But naturally finished products did not have decent moisture resistance. The doctor's compatriot (also a doctor, but in the field of chemistry) Michaelis tried to process the mixture of lime and sand with steam under pressure. So there was a silicate brick. October 5, 1880 can be considered the date of his birth. Moreover, his invention was not based on calculations (like almost all scientific breakthroughs of that time, take at least the biography of Thomas Alva Edison who created the light bulb, phonograph, etc.), but the result of trial and error. "[1]

\footnotetext{
*Corresponding author: igasu_alex@mail.ru
} 


\section{Methods}

\section{Common knowledge}

The technological scheme of manufacturing products includes four main stages:

Stage 1. Preparation of the mixture - the main components and the necessary additives are dosed, which adjust the composition of the mixture and affect the physical and mechanical characteristics of the finished product.

Stage 2. Molding - the composition of the silicate mixture is pressed under pressure of $15 \ldots$ $20 \mathrm{MPa}(150 \ldots 200 \mathrm{kgf} / \mathrm{cm} 2)$ on mechanical presses.

Stage 3. Autoclave processing - molded products are autoclaved with "hot" steam (whose temperature exceeds $100^{\circ} \mathrm{C}$ ) under a pressure of $0.8 \mathrm{MPa}$. This pressure can withstand $6 \ldots$ 8 hours. The pressure in the autoclave is raised and reduced within 1.5 hours. The total steam cycle time is from 10 to 14 hours.

Stage 4. The finished product after unloading from the autoclave is subjected to incoming inspection and packaged for shipment to the consumer in accordance with the requirements of GOST 379-2015 "Brick, stones, blocks and slab partition walls. General technical conditions ", GOST 379-2015“ Silicate bricks, stones, blocks and plates. General technical conditions "establishes brands and types of silicate brick.

It has the following main features:

1. strength grade-M100, M125, M150, M175, M200, M250, M300;

2. frost resistance mark-F15, F25, F35; F45; F50;

3. thermal conductivity- $0.38-0.70 \mathrm{~W} / \mathrm{m}^{\circ} \mathrm{C}$.

According to the species characteristic, solid, hollow, and porous brick are distinguished. In size - single, one and a half, double. By appointment - front and ordinary.

Advantages of silicate brick:

1. Relatively low cost

If you compare silicate brick with clay, then the preferred cost should be given to silicate brick, it is lower by $25 \ldots 30 \%$. The production of silicate brick requires 2.5 times less energy consumption ( 2 times less fuel and 3 times less electricity). In addition, the complexity of manufacturing is 2.5 times lower.

2. Environmentally friendly building material. Consists of components safe for human health. Not a "phonite."

3. Compatible with almost any kind of masonry mortar

4. Has aesthetic properties, can have a wide color gamut.

5. Has a good geometric performance.

6. High strength characteristics. The compressive strength can reach $30 \mathrm{MPa}(300 \mathrm{~kg}$ $1 \mathrm{~cm} 2)$.

7. Good sound insulation due to high specific gravity

8. Relatively high frost resistance - up to 50 freezing and thawing cycles.

9. Relatively easy to process.

10. The material breathes due to its porosity.

Disadvantages of silicate brick:

1. High thermal conductivity. Thermal conductivity $\lambda$ :

- Full-bodied silicate brick $\lambda=$ from 0.7 to $0.8 \mathrm{~W} / \mathrm{m}^{\circ} \mathrm{K}$. The construction of the wall with its use requires serious measures for insulation.

- Silicate, with technical voids $\lambda=0.66 \mathrm{~W} / \mathrm{m}^{\circ} \mathrm{K}$.

- Slit-type silicate brick - the exponent $\lambda$ is similar to the ceramic slab $(0.4) \lambda \mathrm{W} / \mathrm{m}^{\circ} \mathrm{K}$.

2. Relatively heavy

- 15 ... 30\% heavier than ceramic bricks;

- the weight of a single brick is $3.3 \ldots 3.6 \mathrm{~kg}$;

- full body weight $4.0 \ldots 4.3 \mathrm{~kg}$; 
- density of hollow bricks $1135 \ldots 1577 \mathrm{~kg} / \mathrm{m} 3$;

- the density of solid brick $1840 \ldots 1933 \mathrm{~kg} / \mathrm{m} 3$;

3. High water absorption (and hygroscopicity) - up to $7 . .8 \%$ (in special cases, up to $16 \%$ ) by weight and, as a result, rapid destruction upon exposure to moisture. Since it absorbs moisture well and quickly, when performing masonry, an additional technological operation is often required - forced wetting of the brick in order to exclude the rapid absorption of water from the cement-sand mortar. Rain protection required. With oblique rain (rain), unprotected silicate brick masonry can absorb up to 11 liters of moisture per 1 $\mathrm{m} 2$ of surface. It rains, as a rule, in the fall, and a nighttime drop in temperature freezes moisture in the pores. When freezing, moisture increases its volume by $9 \%$ and destroys the outer surface layers of masonry. Due to the high water absorption, a high degree of formation of efflorescence on masonry, which is formed as a result of the migration of salts from masonry mortar, groundwater and even air, is high. The efflorescences on the silicate brick masonry are practically invisible and washed off by rains in the coming years of operation. Salts are removed with acetic acid solution, 5\% hydrochloric acid solution or ammonia solution, after drying, the wall must be covered with alkaline acrylic varnish or aqueous solution of water repellents, or plastered with a waterproof plaster layer. All this leads to higher operating costs.

4. Relatively high brittleness contributes to marriage (cracks, fish, rebounds) with a low culture of transportation and unloading of bricks.

5. Not resistant to acidic and alkaline aggressive environments.

6. Does not withstand high temperatures

It was found that when the silicate brick is heated to $200^{\circ} \mathrm{C}$, its strength increases, then it begins to gradually decrease and at $600^{\circ} \mathrm{C}$ it reaches the initial one. At $800{ }^{\circ} \mathrm{C}$, it decreases sharply due to the decomposition of calcium cement hydrosilicates cementing bricks. An increase in the strength of a brick during its calcination to $200{ }^{\circ} \mathrm{C}$ is accompanied by an increase in the content of soluble $\mathrm{SiO} 2$, which indicates a further course of the reaction between lime and silica. [2].

LITTLE-KNOWN FACTS.

From the latest statistics on fires in the Russian Federation, we can conclude that about $71.1 \%$ of fires occur in residential buildings, $29.4 \%$ of which are built of silicate brick [34]. Therefore, the problem of the influence of high temperatures on structures made of silicate brick is relevant.

The degree of fire resistance of structures made of stone materials can be judged by their actual limits of fire resistance. So, according to the second limit state for fire resistance, walls and partitions of solid and hollow silicate bricks have a fire resistance limit: with a wall thickness of $65 \mathrm{~mm}-0.75 \mathrm{~h}, 120 \mathrm{~mm}-2.5 \mathrm{~h}$, and with a wall thickness of non-loadbearing structures of $250 \mathrm{~mm}$ - not less than 5.5 hours (See the Guidelines for determining the pre-business fire resistance of building structures, fire hazard parameters of materials. Design for fire protection. Reference material. DEVELOPED by OJSC "Research Center" Building "(Doctor of Engineering, Prof. A. I. Zvezdov), Central Research Institute triple constructions (TSNIISK) named after V.A. Kucherenko OJSC "Research Center" Construction "(Doctor of Technical Sciences, Professor II Vedyakov; Doctor of Technical Sciences, Professor Yu.V. .Krivtsov; Ph.D., Senior Researcher I.R. Ladygin; Ph.D., Senior Researcher V.V. Pivovarov; V.V. Yashin; P.P. .Kolesnikov), with the participation of Holding Association KrilaK Association (Doctor of Economics, Prof. A.K. Mikeev; Candidate of Engineering, Senior Researcher E.N. Nosov; M.V. Postnikov)).

In some cases, it is not possible to eliminate the fire in the shortest possible time. During such fires, the room temperature may exceed $1000 \ldots 1500^{\circ} \mathrm{C}$ depending on the following factors: fire load, duration of fire exposure, thermal conductivity of the material, convective processes, etc. An important role is played by the arrival time of the fire 
brigade. In connection with the above facts, in case of fires there is a high probability of exceeding the standard temperature in the body of silicate brick. Silicate products contain a large amount of crystallization water. During hydration reactions that occur during the autoclaving of silicate products, water binds to the formed silicates. On the other hand, due to the porous structure of silicate products, chemically unbound water accumulates in them, and in case of fire, water can boil in the pores of the brick and break, since the volume of water increases by 1700 times during evaporation. This factor reduces the bearing capacity of masonry. Rupture of pores in silicate brick leads to a violation of its structure and, as a consequence, to its destruction.

With prolonged exposure to high temperatures on the brickwork, dehydration of calcium hydrosilicate and calcium oxide hydrate, which bind sand grains, breaks down the brick in the form of hair cracks. These cracks appear both across and along the masonry and can propagate quite deeply into the masonry body. As a result of the intersection of cracks, the masonry is crushed into flakes, as a result of which a partial collapse of the masonry in the zones of its damage can occur. If this happens with a load-bearing wall operating under load from overlying brickwork and ceilings, the situation is exacerbated even more. In this case, the cracks formed are both thermal and forceful. As studies have shown [5, 11], if force cracks pass through four (or even three) rows of silicate brick masonry, then this indicates its emergency state. As a result of the fire, the further use of silicate brick walls is no longer acceptable, without further examination to identify the technical condition of the brickwork and its operability. During fire fighting, there is also a danger of destruction of the brickwork. Currently, fires are extinguished by water, as it is economically viable. The water temperature is much lower (the minimum permissible water temperature in a fire truck is $+15^{\circ} \mathrm{C}$ ) than the temperature in a burning room and on the surface of the masonry itself. With rapid cooling, temperature deformations lead to the appearance of cracks both in individual bricks and in brickwork as a whole. (An example is the task: "How to destroy a stone, being on the bank of the river? Answer:" Roll it into a fire, heat it and push it into a river. "The consequences are obvious)

Under the influence of cold water, masonry may break down, even at temperatures below the standard temperature of using silicate brick. In addition, the pressure in the hose of the hose is from 4 (for the hand barrel type RS-50) to 8 atmospheres (for the gun barrel type LS-C60). Thus, the water jet has an additional force effect on the masonry heated during a fire. The width of the support of reinforced concrete structures on load-bearing walls of small-sized elements, according to the normative literature, should be at least 120 $\mathrm{mm}$. [6]. Often, the heat extinguish the outside of the building. Water enters the heated internal load-bearing wall, a sharp cooling of the masonry surface occurs. Due to the sharp temperature difference, the brick breaks and its layer-by-layer destruction. The higher the temperature of the masonry, the deeper the layer destruction occurs, thereby reducing the area of bearing of the supporting reinforced concrete structure, which can lead to its collapse.

An analysis of modern normative literature regarding the fire-bone of masonry made of silicate brick allows us to conclude that it practically does not take into account and normalize the above aspects. Thus, it is necessary to continue and deepen scientific and practical research in the field of high-temperature effects on silicate brick masonry, followed by the development of amendments to the regulatory literature related to the technical diagnostics of fire-exposed silicate brick structures. As well as technical regulations on the tactics of extinguishing fires from buildings made of silicate brick.

\section{Results}


As an example and confirmation of the above little-known facts of the behavior of masonry under high-temperature influences, you can familiarize yourself with the studies [7-10]. In [11], an algorithm was developed for the possible collapse of masonry as a result of a decrease in its bearing capacity due to a fire. To simulate this situation, we examined the internal load-bearing wall of a five-story brick building $380 \mathrm{~mm}$ thick made of brick of the M100 grade (grade of mortar M50 according to GOST 379-2015. The brick and stones are silicate. Technical conditions, floor height $-3,0 \mathrm{~m}$, the span of the room is $6 \mathrm{~m}$, the area of support of the floor slabs is $1 \times 0.12 \mathrm{~m}$.

In the table. 1 shows the parameters of the loads on the floor.

It is also necessary to take into account the load from the overlying masonry of a brick wall. In the framework of this task, we take for calculation only the weight of the part of the wall located above the supporting platform of the plates. The total height of the wall sections taken into account in the calculation is $4 \cdot 3=12 \mathrm{~m}$. The average masonry density is $1800 \mathrm{~kg} / \mathrm{m} 3$. The load is calculated per $1 \mathrm{~m}$ of the width of the bearing pad, the length of the bearing pad is $0.12 \mathrm{~m}: 0.12 \cdot 1 \cdot 12 \cdot 1800=2592 \mathrm{~kg}$. The wall load under the ceiling at the first floor ceiling is: $(\mathrm{q} \cdot 1 / 2) \cdot 5+2592=(637 \cdot 6 / 2) \cdot 5+2592=12147 \mathrm{~kg}$, where $\mathrm{q}$ is the calculated load on the ceiling; 1 - span of the plate.

Table 1. Overlap load parameters

\begin{tabular}{|l|l|l|l|}
\hline Name & $\begin{array}{l}\text { Normative } \\
\text { load, } \\
\mathrm{kN} / \mathrm{m} 2\end{array}$ & $\begin{array}{l}\text { Coefficient } \\
\text { reliabilities } \\
\text { by load, } \gamma \mathrm{f}\end{array}$ & $\begin{array}{l}\text { Calculated } \\
\text { load, } \\
\mathrm{kN} / \mathrm{m} 2\end{array}$ \\
\hline I. Constant load: & & & \\
\hline 1. Parquet floors, stacked & 0,06 & 1,1 & 0,07 \\
\hline 2. Fibreboard & 0,06 & 1,1 & 0,07 \\
\hline 3. Cement screed-2 cm & 0,38 & 1,3 & 0,50 \\
\hline $\begin{array}{l}\text { 4. Expanded clay concrete-4 cm } \\
(\rho=800 \mathrm{~kg} / \mathrm{m} 3)\end{array}$ & 0,32 & 1,3 & 0,42 \\
\hline 5. Vapor barrier & 0,05 & 1,2 & 0,06 \\
\hline $\begin{array}{l}\text { 6. Ferroconcrete } \\
\text { hollow plate } \mathrm{h}=22 \mathrm{~cm}\end{array}$ & 3,00 & 1,1 & 3,30 \\
\hline Total: & 3,87 & 4,42 & \\
\hline II. Temporary load: & & & 1,95 \\
\hline $\begin{array}{l}\text { Apartments for residential } \\
\text { buildings }\end{array}$ & 1,50 & 1,3 & \\
\hline Total: & 5,37 & 6,37 & \\
\hline
\end{tabular}

The voltage at the same level will be:

where $\mathrm{N}$ is the longitudinal force;

$$
\sigma=\mathrm{N} / \mathrm{A}=12147 / 1200=10.123 \mathrm{kgf} / \mathrm{cm}^{2},
$$

A is the bearing area of the plate $\left(12 \mathrm{~cm} \times 100 \mathrm{~cm}=1200 \mathrm{~cm}^{2}\right)$.

According to [6], the ultimate bearing capacity of the masonry is $1.5 \mathrm{MPa}$. With a decrease in the support area of the floor slab by $39 \mathrm{~mm}$ (against the normalized $120 \mathrm{~mm}$ ), the stress in the masonry reaches its ultimate bearing capacity. A further decrease in the bearing area will lead to inevitable collapse. 
Calculations carried out according to the method of [9] show that when the temperature is applied at $1000^{\circ} \mathrm{C}$ to the masonry for $50 \mathrm{~min}$, the masonry decomposes to a depth of 39 $\mathrm{mm}$. To verify the theoretical data obtained from the walls of the building in which the fire occurred, samples of silicate brick were selected (5 lots of 2 bricks). The fire in the building lasted 4-4.5 hours. The height of the room is $3.1 \mathrm{~m}$. A general view of the walls of a building after a fire is shown in Fig. 1 and 2.

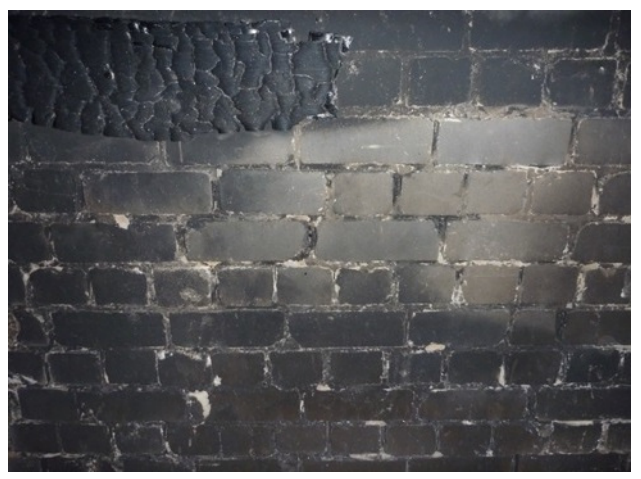

Figure 1. General view of the wall of the building after the fire.

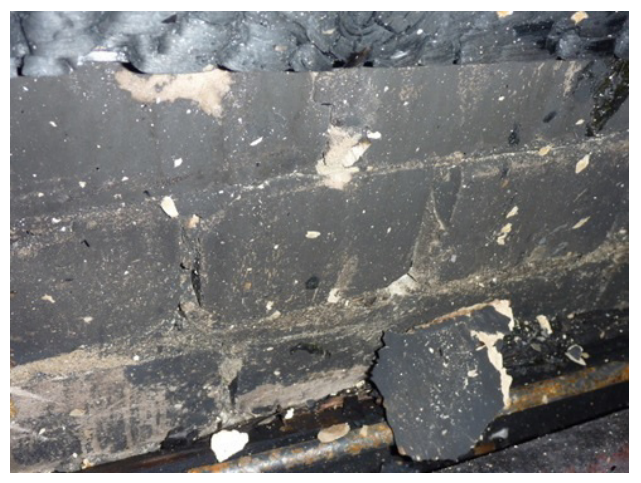

Figure 2. Dehydration of the surface layer of silicate brick.

Samples of all five batches selected by height were tested in the P-125 press (Fig. 3).

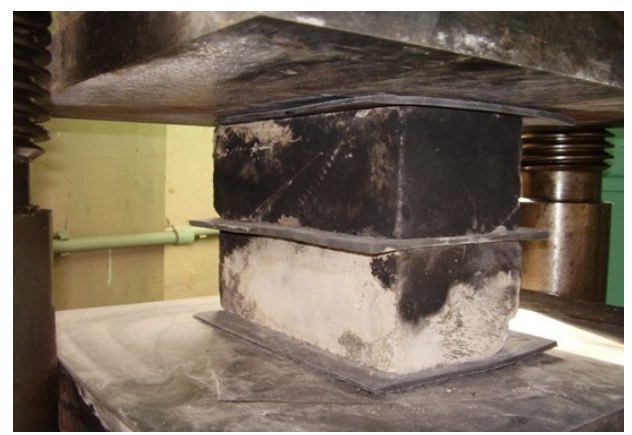

Figure 3. General view of the samples placed in the press P-125, before the test. 
According to the test results, we can conclude that the decrease in the strength of silicate brick along the height of the wall occurs unevenly.

This is due to the fact that the indoor temperature during a fire is higher in the floor than in the floor. The test results are shown in table. 2

Table 2. Test results of selected samples in the press P-125

\begin{tabular}{|l|l|l|l|l|}
\hline $\begin{array}{l}\text { The } \\
\text { consignment }\end{array}$ & $\begin{array}{l}\text { Height } \\
\text { selection's } \\
\text { sample's, } \\
\text { mm }\end{array}$ & $\begin{array}{l}\text { Strength of silicate brick taken } \\
\text { from the wall of a building not } \\
\text { subjected to high temperature } \\
\text { impact, MPa }\end{array}$ & $\begin{array}{l}\text { The strength of the } \\
\text { sample after high } \\
\text { temperature exposure, } \\
\text { MPa }\end{array}$ & $\begin{array}{l}\text { The } \\
\text { decrease in } \\
\text { strength of } \\
\text { the } \\
\text { sample, } \%\end{array}$ \\
\hline 1 & 3000 & $9,73(\mathrm{M} 100)$ & 4,34 & 55 \\
\hline 2 & 2400 & 4,93 & 49 & \\
\hline 3 & 1800 & 5,79 & 40 & \\
\hline 4 & 1200 & 6,32 & 35 & \\
\hline 5 & 600 & 6,71 & 31 & \\
\hline
\end{tabular}

For greater clarity, according to the table.2 is a graph of the decrease in strength of silicate brick along the height of the wall (Fig. 4).

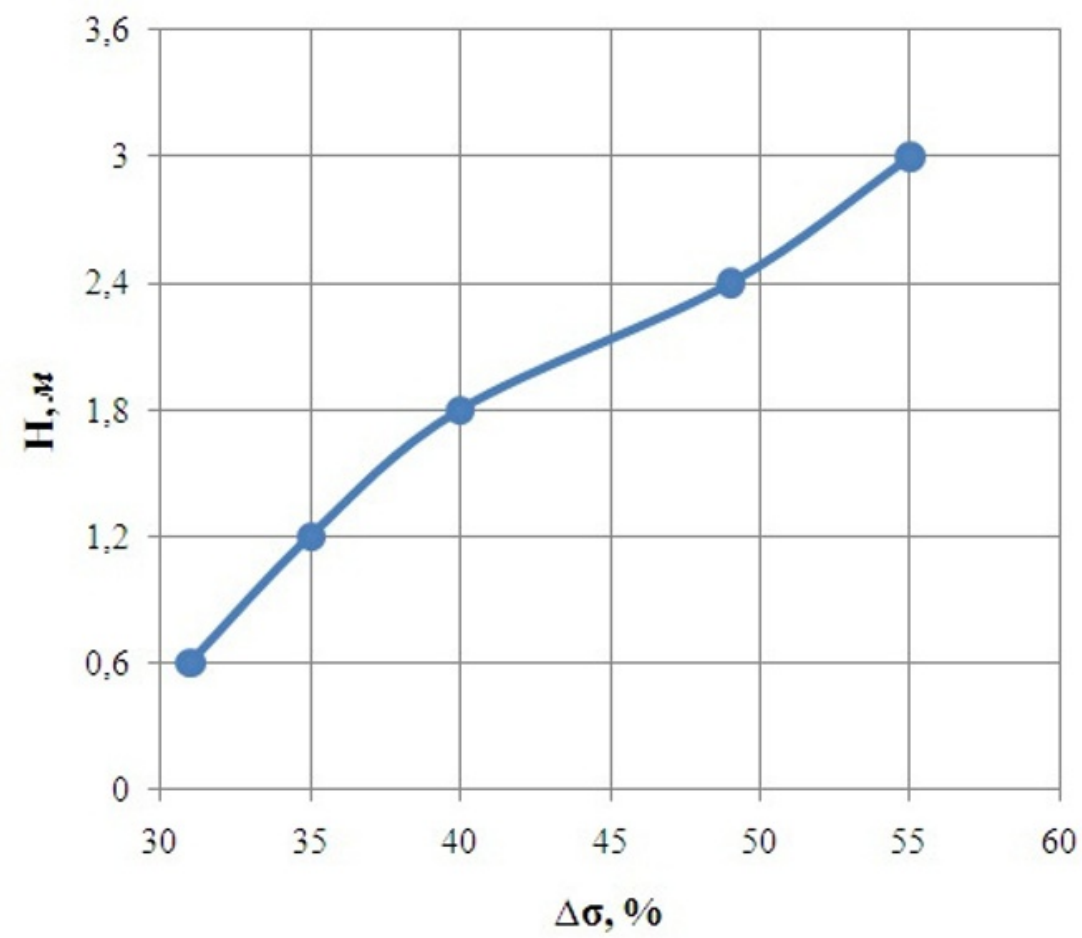

Fig. 4. The schedule for reducing the strength of silica brick at the height of the wall.

In some cases, it is impossible to visually determine the degree of destruction of the construction after a fire, since it is expressed as a violation of the structure of silicate brick and masonry as a whole, and this reduces the bearing capacity. This situation is very dangerous, since there is a chance of a sudden and avalanche collapse. 


\section{Conclusions}

From the foregoing, we can conclude that after a fire in the room there is a need for an instrumental examination of structures in order to determine the possibility of its further normal operation, even if there are no external signs of destruction.

\section{References}

1. https://srbu.ru/stroitelnye-materialy/238-silikatnyj-kirpich-plyusy-i-minusy.html

2. http://khsm.com.ua/poleznaya-informatsiya/95-silikatniy-kirpich/130-silikatnyjkirpich-fizicheskie-kharakteristiki

3. Information and analytical information on the housing stock of the Russian Federation, [http://www.comhoz.ru/content/document_r_F5765910-BD6A-470F-89F0FAF5F4E1F504.html].

4. Gnedina L. Yu. Building materials, 12. Pp. 18, 19 (2012)

5. Bedov A. I., Gabitov A. I. Design, restoration and strengthening of stone and reinforced stone structures: textbook. (Moscow: publishing house DIA, 2008)

6. Fedosov S. V., Ibragimov A. M., Gnedin L. Yu., Smirnov A. Yu. Building materials, 11. 60-61 (2008)

7. Fedosov S. V., Ibragimov a.m., Gnedina L. Yu., Smirnov A. Yu, Building materials, 9, 48-49 (2009)

8. Fedosov S. V., Ibragimov A. M., Soloviev R. A., Murzin N. V., Tarakanov D. V., Lapshin S. S. Vestnik MGSU, 4. Pp. 121-128 (2013)

9. Koshmarov Yu. a., Lapshin S. S., Tarakanov D. V. Fires and emergency situations: prevention, liquidation, 1, 67-75.(2009)

10. Ibragimov a.m., Gnedina L. Yu., Smirnov A. Yu., Soloviev R. A, Vestnik of civil engineers, 4 (39). 54-58 (2013) 